\title{
LIDMAN, Satu, Zum Spektakel und Abscheu. Schand- und Ehrenstrafen als Mittel öffentlicher Disziplinierung in München um 1600
}

Falk Bretschneider

\section{CpenEdition}

Édition électronique

URL : http://journals.openedition.org/ifha/1840

DOI : $10.4000 /$ ifha. 1840

ISSN : 2198-8943

Éditeur

IFRA - Institut franco-allemand (sciences historiques et sociales)

Référence électronique

Falk Bretschneider, «LIDMAN, Satu, Zum Spektakel und Abscheu. Schand- und Ehrenstrafen als Mittel öffentlicher Disziplinierung in München um $1600 »$, Revue de l'IFHA [En ligne], Date de recension, mis en ligne le 01 janvier 2009, consulté le 22 septembre 2020. URL : http://journals.openedition.org/ifha/ 1840 ; DOI : https://doi.org/10.4000/ifha.1840

Ce document a été généré automatiquement le 22 septembre 2020.

(CIFHA 


\title{
LIDMAN, Satu, Zum Spektakel und Abscheu. Schand- und Ehrenstrafen als Mittel öffentlicher Disziplinierung in München um 1600
}

\author{
Falk Bretschneider
}

Pour nombre d'historiens, l'appareil répressif de l'époque moderne reste synonyme d'exécutions, de mutilations et autres peines corporelles, bref : d'un régime de sanctions portant atteinte à l'intégrité physique dont la fascination terrifiante ne cesse, apparemment, de produire son effet. En fait, la réalité était tout autre. Certes, les autorités judiciaires avaient, de temps en temps, recours à l'un de ces grands rituels punitifs à la scénographie minutieuse que l'historiographie a longtemps pris pour monnaie courante. Toutefois, se basant sur l'« honorabilité " comme catégorie fondamentale des rapports à l'intérieur des sociétés, l'esprit de la plupart des sanctions prononcées par la justice pénale moderne n'était pas d'infliger au condamné une lésion physique mais d'atteindre sa réputation et son honneur (même si, pour arriver à cette fin, des actes afflictifs ne furent pas rares). Ce constat est confirmé par l'ouvrage de S.M. qui étudie le rôle des peines infamantes à Munich entre 1596 et 1618. Le texte qui trouve son origine dans une thèse soutenue, en 2008, à l'Université de Joensuu (Finlande) s'appuie sur le dépouillement d'un riche fonds d'archives locales, alors que son cadre théorique est constitué par le processus de disciplinarisation, une approche que S.M. qualifie elle-même de " position méthodologique naturelle » (p. 15), sans dire pour autant ce qu'elle entend concrètement par cela. Dans son introduction, l'auteure examine de manière sommaire l'état actuel des recherches sur le sujet pour revenir, ensuite, aux travaux antérieurs de l'histoire du droit dans lesquels elle trouve la distinction, essentielle pour son analyse, entre peines d'opprobre et peines déshonorantes (Schand- et Ehrenstrafen), les unes étant fondées sur une perte de l'honneur « social », les autres sur une stigmatisation permanente et la déperdition de l'honneur « juridique». 
2 Consacrée à une étude globale de la notion d'« honneur ", la première partie du livre renseigne d'abord sur les significations complexes que revêt celle-ci en tant que code social et capital symbolique, ainsi que sur ses dimension sociétales ("bona fama ») et juridiques (" dignitas civilis »). L'auteure retrace ensuite la législation territoriale bavaroise et l'état de l'administration locale munichoise pour placer la pratique pénale qu'elle étudie dans le contexte d'une disciplinarisation des populations par les autorités. Après avoir décrit les origines canoniques et séculières des peines infamantes, la partie se termine par une analyse de l'« infamie » des agents d'exécution (non sans importance pour l'effet humiliant des peines) et par une définition des ressemblances et différences entre peines d'opprobre et peines déshonorantes dans leurs dimensions sociales et symboliques. La partie suivante est entièrement consacrée à une étude de toutes les peines infamantes jamais prononcées à Munich : la prison (dont S.M. souligne l'existence dès le XVIe s. et le caractère contradictoire de son effet infamant ; en fait, celui-ci variait fortement en fonction de la durée de l'incarcération, des lieux utilisés ou du fait que la sanction était ou non précédée par la torture) ; les peines d'opprobre (par exemple l'amende honorable faite publiquement, l'exposition devant l'église ou, variante séculière, sur la place de l'hôtel de ville, mais aussi la condamnation aux travaux forcés ou à une chaîne fixée aux pieds que le coupable était contraint de porter à toute heure, y compris lors de ses déplacements en ville...) ; les peines déshonorantes (par exemple l'humiliation publique, le pilori, la fustigation, la mutilation, la stigmatisation au fer rouge, les diverses formes du bannissement...). Toutes ces sanctions sont analysées dans les détails de leur application, dont les fortes variations montrent à nouveau l'extrême flexibilité et la variabilité de l'appareil répressif moderne. La troisième partie du livre, enfin, donne un vaste panorama de cas concrets, organisés autour de trois champs de délits (alcool et violence, formes déshonorantes de la subsistance, sexualité) pouvant mener à la condamnation à une peine infamante.

3 Avec cet ouvrage, S.M. parvient sans aucun doute à mettre en valeur le caractère fondamental de l'honneur comme grandeur sociale à l'époque moderne. À l'instar d'autres travaux sur l'histoire de la criminalité et de la justice pénale, l'étude est axée sur une analyse des conflits découlant des multiples efforts consentis par les autorités pour définir, dans la perspective d'une disciplinarisation globale de la société, le comportement des populations. Cette démarche méthodologique constitue à la fois la force et la faiblesse du livre. Car (a-t-on encore besoin de le rappeler ?), comme toute construction sociale, l'honneur ne saurait se résumer à un conflit entre autorités qui encadrent et sujets qui subissent ou se révoltent. En fait, la concentration de l'étude sur le domaine de la justice pénale masque tous ces conflits circulant entre judiciaire et infrajudiciaire, c'est-à-dire toutes les interactions horizontales entre les différents acteurs sociaux dans le but de déterminer, de négocier et de garantir l'honneur de sa propre personne ou du groupe social auquel on appartient, à l'aide ou non de la justice pénale. De même, on peut regretter l'absence de toute quantification qui aurait permis de mieux mesurer le poids des peines infamantes au sein de l'ensemble de l'appareil répressif munichois. Enfin, la distinction entre peines d'opprobre et peines déshonorantes que S.M. emprunte à l'historiographie traditionnelle du droit représente, certes, un schéma utile pour mettre de l'ordre dans ce capharnaüm que sont les peines modernes. Mais son intérêt s'arrête là. C'est donner aux normes juridiques une validité ontologique au-delà du jeu social que d'introduire une semblable délimitation entre honneur « social » et honneur « juridique ». Le contresens 
d'une telle démarche finit par se faire jour à la fin du livre où l'auteure donne, $\mathrm{p}$. 373-375, une vue synoptique de toutes les peines infamantes prononcées à Munich pendant la période étudiée. Intéressant, certainement, pour mieux comprendre la diversité des sanctions appliquées, ce tableau devient fort douteux quand il propose, pour chaque peine examinée, une appréciation de son effet infamant sur une échelle allant de 1 à $10 .$. À de telles maladresses près, pourtant, l'ouvrage de S.M. reste un travail respectable qui offre une prise de contact facile et approfondie avec une importante pratique pénale moderne.

4 Falk BRETSCHNEIDER (École des Hautes Études en Sciences Sociales, Paris) 